\title{
Beamlines of the biomedical imaging and therapy facility at the Canadian Light Source - Part 2
}

\section{Wysokinski, T.W.}

2013

Wysokinski , T W , Chapman , D , Adams , G, Renier , M , Suortti , P \& Thomlinson , W 2013 , ' Beamlines of the biomedical imaging and therapy facility at the Canadian Light Source - Part 2 ' , Journal of Physics : Conference Series , vol. 425 , no. PART 7 . https://doi.org/10.1088/1742-6596

http://hdl.handle.net/10138/162090

https://doi.org/10.1088/1742-6596/425/7/072013

cc_by

publishedVersion

Downloaded from Helda, University of Helsinki institutional repository.

This is an electronic reprint of the original article.

This reprint may differ from the original in pagination and typographic detail.

Please cite the original version. 
Beamlines of the Biomedical Imaging and Therapy Facility at the Canadian Light Source Part 2

This content has been downloaded from IOPscience. Please scroll down to see the full text. 2013 J. Phys.: Conf. Ser. 425072013

(http://iopscience.iop.org/1742-6596/425/7/072013)

View the table of contents for this issue, or go to the journal homepage for more

Download details:

IP Address: 128.214.163.19

This content was downloaded on 16/05/2016 at 09:22

Please note that terms and conditions apply. 


\title{
Beamlines of the Biomedical Imaging and Therapy Facility at the Canadian Light Source - Part 2.
}

\author{
T W Wysokinski ${ }^{1}$, D Chapman ${ }^{2}$, G Adams $^{3}$, M Renier ${ }^{4}$, P Suortti $^{5}$ \\ and $W$ Thomlinson ${ }^{1}$ \\ ${ }^{1}$ Canadian Light Source, Saskatoon, SK, Canada \\ ${ }^{2}$ Anatomy and Cell Biology, University of Saskatchewan, Saskatoon, SK, Canada \\ ${ }^{3}$ Western College of Veterinary Medicine, Saskatoon, SK, Canada \\ ${ }^{4}$ European Synchrotron Radiation Facility, Grenoble, France \\ ${ }^{5}$ Department of Physics, University of Helsinki, Finland \\ E-mail: bmit@lightsource.ca
}

\begin{abstract}
The BioMedical Imaging and Therapy (BMIT) facility provides a world class facility with unique synchrotron-specific imaging and therapy capabilities. This paper describes Insertion Device (ID) beamline 05ID-2 with the beam terminated in the first experimental hutch: POE-2. The experimental methods available in POE-2 include: Microbeam Radiation Therapy (MRT), Synchrotron Stereotactic Radiation Therapy (SSRT) and absorption imaging (projection and Computed Tomography (CT)). The source for the ID beamline is a multi-pole superconductive $4.3 \mathrm{~T}$ wiggler, which can generate $\sim 30 \mathrm{~kW}$ of radiative power and deliver dose as high as $3000 \mathrm{~Gy} / \mathrm{s}$ required for MRT program. The optics in POE-1 hutch prepares either monochromatic or filtered white beam that is used in POE-2. The Double Crystal (DC), bent Laue monochromator will prepare a beam over $10 \mathrm{~cm}$ wide at sample point, while spanning an energy range appropriate for imaging studies of animals $(20-100+\mathrm{keV})$. The experimental hutch will have a flexible positioning system that can handle subjects up to $120 \mathrm{~kg}$. Several different cameras will be available with resolutions ranging from $4 \mu \mathrm{m}$ to $150 \mu \mathrm{m}$. The latest update on the status of 05B1-1 bending magnet (BM) beamline, described in Part 1 [1], is also included.
\end{abstract}

\section{Introduction}

The BMIT facility will provide unique synchrotron-specific X-ray imaging and therapy capabilities [2]-[3]. As compared with other biomedical facilities in the world BMIT facility implements high load positioning systems and dedicated DEI setups for both BM and ID beamlines. It will be used to address unsolved problems in medicine (human and animal), agriculture, and other biomedical sciences. The BMIT facility is accessed for experiments in two hutches, POE-2 and SOE-1 (See Figure 1 in [1]).

The ID beamline shares POE-2 with the BM beamline for experiments. One advantage is that it will be possible to quickly move the subject between the BM and ID beams in POE-2 for imaging and therapy tests or to run two sets of experiments in parallel.

The Insertion Device beamline is intended to be used for testing of new ideas in imaging and therapy and to validate techniques initially developed on the bend magnet beamline including novel monochromators designs, near-edge and multi-energy imaging systems and new dosimetry 
methods. Additionally, the ID beamline will host new imaging methods, such as imaging based on structural aspects of tissues by diffraction, absorption spectroscopy imaging, fluorescence imaging, and others. Such tissue characterization methods may form the basis of programs that will translate to clinical settings.

\section{Source and Front End}

\subsection{Insertion Device - BMIT Multi-pole (25+2) Superconducting Wiggler}

The Insertion Device [see Table 1] is multi-pole, cold-bore wiggler (1.4-4.3 Tesla with a period length of $48 \mathrm{~mm}$, stored energy of $27 \mathrm{~kJ}$ and a pole gap of $14.5 \mathrm{~mm}$ ) uses Nb-Ti superconductive wire and was designed [4] and fabricated [5] to provide a high energy spectrum $\left(E_{C}>20 \mathrm{keV}\right)$ with a wide beam fan $(\mathrm{K} \sim 20)$.

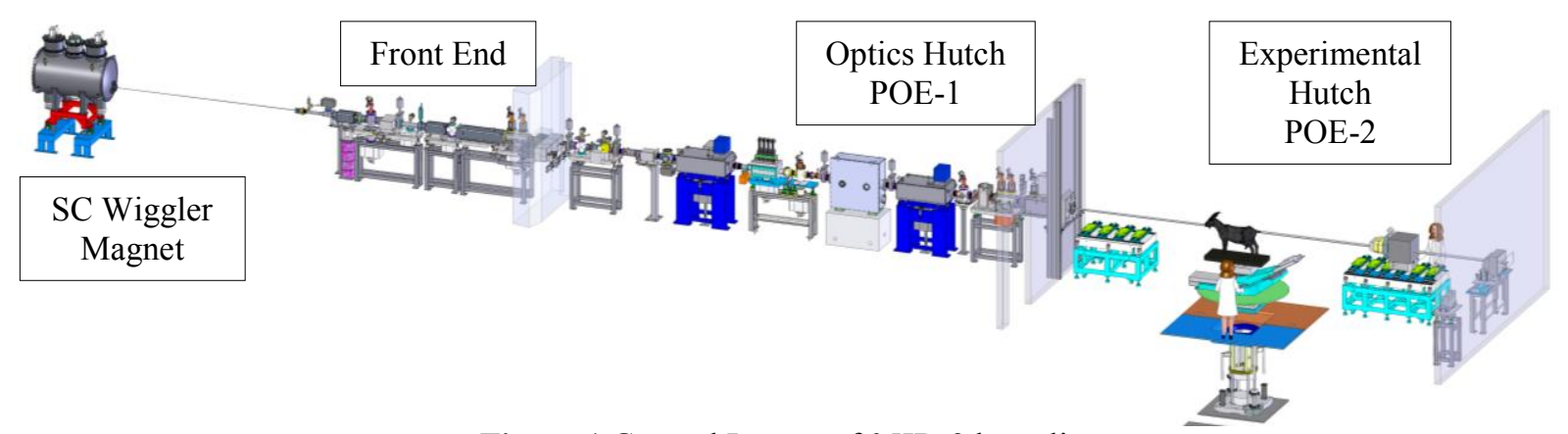

Figure 1 General Layout of 05ID-2 beamline

It has very high field/period ratio which allows effective use of radiation. Due to unique spectral properties of the source special care was required to design the shielding for the hutches [6].

Table 1 Wiggler Specifications

\begin{tabular}{lll}
\hline Parameter & Value & Unit \\
\hline Magnetic Field, $\mathrm{B}_{0}(\max )$ & 4.3 & $\mathrm{~T}$ \\
Critical Energy, $\mathrm{E}_{\mathrm{C}}(\max )$ & 24 & $\mathrm{keV}$ \\
Period Length, $\lambda_{0}$ & 4.8 & $\mathrm{~cm}$ \\
Deflection Parameter, K (max) & 19.3 & $\mathrm{~K} / \gamma \sim 3.4 \mathrm{mrad}$ \\
Photon Range & $0.1-0.6$ & $\AA$ \\
Energy Range & $20-100+$ & $\mathrm{keV}$ \\
$\mathrm{N}$ (full + half field) & $25+2$ & periods \\
Peak Power Density & & $\mathrm{W} / \mathrm{mm}^{2}$ \\
\hline
\end{tabular}

a 26.5 meters $(500 \mathrm{~mA}, 2.9 \mathrm{GeV})$

The liner of the wiggler, an ultra-high vacuum (UHV) chamber (with 50x10 mm aperture) which is part of the Storage Ring, is cooled to $\leq 20 \mathrm{~K}$. Magnet structure, which is designed to operate at $\leq 4.2 \mathrm{~K}$, is submerged in $\sim 3001$ of Liquid Helium (LHe) contained in LHe vessel - the cryostat. The cryostat is shielded from room temperature by two copper shields: $10 \mathrm{~K}$ and $30 \mathrm{~K}$, cooled with two RDK-408S2 Sumitomo cryocoolers. The cryogenic system for the wiggler is capable of keeping helium consumption (including 6-8 ltr per quench boil-off), close to zero by using a second pair of RDK-415D Sumitomo cryocoolers as recondensers. The LHe tank with the magnet is suspended 
on Kevlar fiber ribbons used for precise alignment of the magnet axis with e-beam axis. The magnet is energized with four $300 \mathrm{~A} / 10 \mathrm{~V}$ power supplies. The control of the wiggler is achieved with a combination of a Junction Box and the MOXA PC and is integrated with facility EPICS system.

\subsection{Front End components}

The insertion device front end is typical of many CLS beamlines [7]-[8], except for the much higher power loads and radiation level observed [9]. The maximum horizontal photon beam angle is $6.4 \mathrm{mrad}$ of which the ID beamline utilizes the central $4 \mathrm{mrad}$. The optics hutch allows both monochromatized beam and filtered white beam to be used in the experimental hutch. The monochromator will prepare a beam-width in excess of $100 \mathrm{~mm}$ with an energy range $(20-100+\mathrm{keV})$ appropriate for imaging studies in small and larger animal (up to sheep size) systems. The expected brightness of the source is $3 \times 10^{12} \mathrm{ph} / \mathrm{s} / \mathrm{mA} / \mathrm{mrad}^{2} / 0.1 \% \mathrm{BW} @ 20 \mathrm{keV}$.

The main components [9] of the Front End (FE) are: SC ID source, two fixed masks, (X-ray beam positioning monitor - optional), collimator, fixed mask, photon shutter, two safety shutters, wall collimator and two beryllium (Be) windows. The second beryllium window isolates the storage ring vacuum section from the beamline vacuum section. Main scatterers such as fixed masks and photon shutter, have additional local shielding (3-6 mm of lead) installed to protect the wiring and cooling water lines as well as to minimize the radiation thru the ventilation chicane in the storage ring roof.

\section{POE-1 (Optics Hutch)}

The main components [10] within the optics hutch are: fixed mask and collimator, (X-ray beam positioning monitor - optional), primary photon slits, filter assembly, wire beam positioning monitor, Double Crystal monochromator, secondary photon slits, (fluorescent view screen for mono beam optional), photon shutter with tungsten backing, fast shutter for MRT, two safety shutters [11] and in-wall collimator - see Figure 1. There are several high capacity ion pumps installed there to deal with outgassing from the monochromator and the MRT shutter. The vacuum section of POE-1 is isolated from air by the last optical component, the Be/Al windows set located in POE-2.

Table 2 MRT Lift Loads, Ranges and Accuracy Requirements [12]

\begin{tabular}{lll}
\hline Parameter & Value & Unit \\
\hline Rated Vertical Load & $120(265)$ & $\mathrm{kg}(\mathrm{lb})$ \\
Vertical translation stage travel range & 700 & $\mathrm{~mm}$ \\
Horizontal translation stage range & $+/-50$ & $\mathrm{~mm}$ \\
Goniometer Ranges & $360^{\circ}$ & degree \\
Maximum Height at lowest position & 2600 & $\mathrm{~mm}$ \\
Lift Weight & $2500(5511)$ & $\mathrm{kg}(\mathrm{lb})$ \\
Kappa Angle & $30^{\circ}$ & degree \\
X,Y sample stage range & $+/-50$ & $\mathrm{~mm}$ \\
Z sample stage range & $+/-25$ & $\mathrm{~mm}$ \\
Sample height above the positioning system & 1000 & $\mathrm{~mm}$ \\
Maximum Speed Z $\mathrm{scAN}$ & 200 & $\mathrm{~mm} / \mathrm{s}$ \\
Dynamic Stability $(\Delta \mathrm{y} / \Delta \mathrm{z}) @$ Z $\mathrm{Z}$ scanning speed & 0.005 over 1 & $\mathrm{~mm}$ over mm \\
Positional Repeatability & 0.025 & $\mathrm{~mm}$ \\
Working radius & $<2500$ & $\mathrm{~mm}$ \\
\hline
\end{tabular}




\section{POE-2 (Experimental Hutch)}

POE-2 hutch was designed to accommodate as many experimental modes as possible, and to provide enough space for users to set up their own experiment equipment. The optics table in front of the hutch will hold shutters, collimators as well as ion chambers and other optical components. For the large samples we plan to use the MRT Lift [12] positioning system - capable of holding samples up to $120 \mathrm{~kg}$. KOHZU stages located on the second optics table will be used for smaller samples. The second optics table will also hold ion chambers and the recording system: film, plates or cameras. At the MRT Lift location, 26.5 meters from the source, the beam is $106 \mathrm{~mm}$ wide and 5.3 $\mathrm{mm}$ high. To record it, several different wide screen cameras will be used with resolution ranging from $4 \mu \mathrm{m}$ to $150 \mu \mathrm{m}$. The beam terminates in the water-cooled beam stop 32 meters from the source. User accessible chicanes facilitate installation of temporary wiring or water lines during experiments.

\section{05B1-1 Beamline Status Update}

The BMIT bend magnet beamline [1] started normal operation in 2011. Four in-vacuum components have been removed due to budget constraints: wire beam positioning monitor, secondary photon slits, fluorescent view screen and the fast imaging shutter. Three components have been added: in-vacuum collimator, high stability granite stand for DEI and high capacity camera positioner. The beamline is fully utilized at this point and around 60 experiments are performed annually.

\section{Conclusions and Discussion}

The BMIT ID POE-2 endstation provides both monochromatic beam as well as filtered white beam. The filtered white beam will deliver up to $3000 \mathrm{~Gy} / \mathrm{s}$. The energy range will be from $\sim 20 \mathrm{keV}$ to over $100 \mathrm{keV}$ with beam width up to $10 \mathrm{~cm}$. The insertion device beamline is designed for imaging and therapy research primarily in biomedical systems from mice to humans, as well as tissue specimens including plants. Core research programs include human and animal reproduction, cancer imaging and therapy, spinal cord injury and repair, cardiovascular imaging and disease, bone growth and development, mammography, developmental biology, gene expression research, development of new imaging methods as well as extending present imaging capabilities.

\section{Acknowledgements}

The Canadian Light Source is supported by the Natural Sciences and Engineering Research Council of Canada, the National Research Council Canada, the Canadian Institutes of Health Research, the Province of Saskatchewan, Western Economic Diversification Canada, and the University of Saskatchewan.

\section{References}

[1] Wysokinski T W et al 2007 NIM A 582 (1) pp 73-76

[2] Thomlinson W C 2005 NIM A 543 (1) pp 288-296

[3] Chapman D 2006 CLSI Document No. 26.2.1.2

[4] Sitnikov A and Blomqvist I 2005 CLSI Document No. 5.8.25.5

[5] Khrushchev S V et al 2009 NIM A 603 (1-2) pp 7-9

[6] Chapman D 2007 CLSI Document No. 26.2.35.1

[7] Dallin L O 2001 CLSI Document No. 5.2.31.2

[8] Mullin C 2005 CLSI Document No. 5.4.1.1

[9] Nagarkal V 2007 CLSI Document No. 26.2.26.1

[10] Smith S 2007 CLSI Document No. 26.8.33.3

[11] Mullin C 2008 CLSI Document No. 26.2.47.1

[12] Wysokinski T W 2006 CLSI Document No. 26.8.1.3 